\title{
A Phase 3b Safety Study of Intravenous (IV) NEPA for Prevention of Chemotherapy-Induced Nausea and Vomiting (CINV) in Breast Cancer (BC) Patients Receiving Anthracycline/Cyclophosphamide (AC)
}

Lee Schwartzberg', Silvia Sebastiani²

${ }^{1}$ Hematology \& Oncology, West Cancer Center, Germantown, TN; ${ }^{2}$ Helsinn Healthcare, Lugano, Switzerland

\section{BACKGROUND}

- In patients receiving highly emetogenic chemotherapy (HEC), anthracycline/cyclophosphamide (AC) or carboplatin, the MASCC antiemetic guidelines recommend the prophylactic triplet combination of an $\mathrm{NK}_{1}$ receptor antagonist (RA) 5-HT $\mathrm{RA}_{3}$, and dexamethasone (DEX) prior to chemotherapy. ${ }^{1}$

- NEPA is the first and only fixed antiemetic combination agent, comprised of netupitant, a highly-selective NK receptor antagonist (RA) and palonosetron (PALO), an established pharmacologically and clinically distinct $5-\mathrm{HT}_{3} \mathrm{RA}$.

- Approval of oral NEPA (netupitant 300 mg/PALO $0.50 \mathrm{mg}$ ) was based on studies demonstrating that a single oral NEPA capsule plus DEX given prior to cisplatin- and AC-based chemotherapy demonstrated superior prevention of CINV over PALO plus DEX for 5 days post-chemotherapy.

\section{Complete Response (No Emesis/No Rescue Use) Rates} from Pivotal Oral NEPA Trials

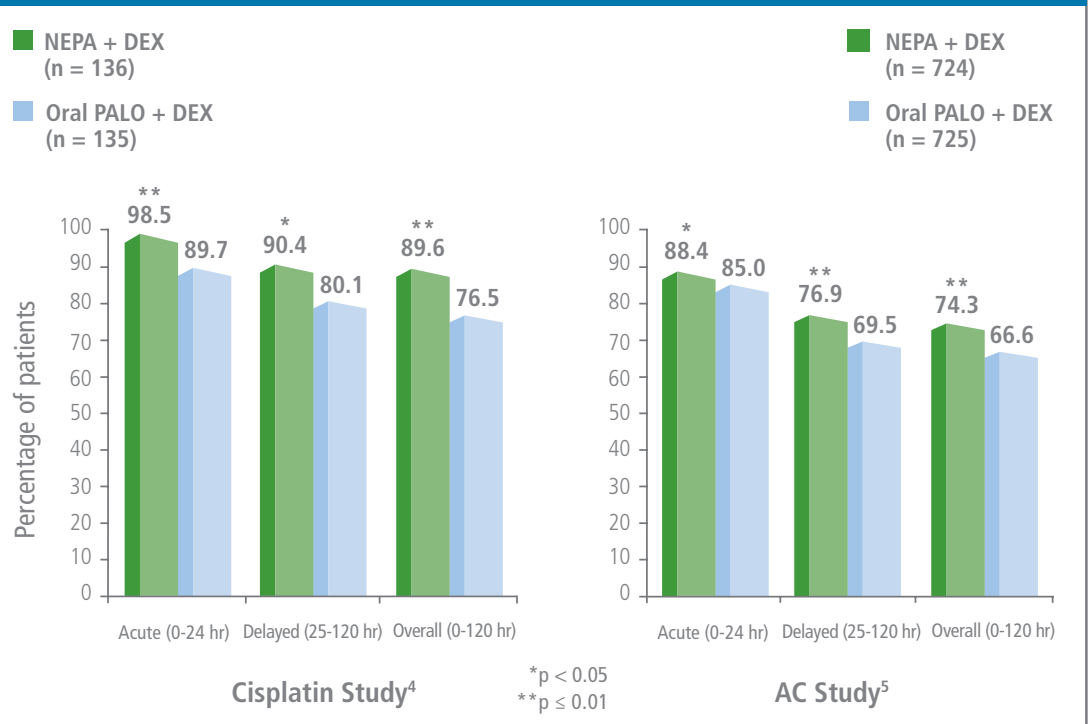

- The safety of oral NEPA was also well-established in the Phase 2/3 clinical program in 1169 NEPA-treated patients in single and repeated cycles. ${ }^{6}$

- To offer additional convenience for patients and healthcare practitioners, a fixed intravenous (IV) combination formulation of NEPA was developed using a water-soluble phosphorylated pro-drug of netupitant, fosnetupitant.

- Differently from other IV NK, RAs, fosnetupitant does not require any surfactant, emulsifier or solubility enhancer to get a clear injectable solution. The formulation of IV NEPA has been simplified reducing the number of excipients and associated toxicities.

- In early phase studies, IV fosnetupitant hydrochloride chloride at dosages of 20-390 mg had been administered to approximately 180 healthy volunteers, with a good safety profile.

- The selected bioequivalent dose of fosnetupitant for the IV formulation is $235 \mathrm{mg}$ (corresponding to a dose of $260 \mathrm{mg}$ of fosnetupitant chloride). The selected IV dose for palonosetron is $0.25 \mathrm{mg}$, the same registered dose of Aloxi ${ }^{\circledR}$ IV

- Given the demonstrated bioequivalence of fosnetupitant and netupitant, a Phase 3 registration study was designed and subsequently demonstrated the safety and tolerability of a single dose of IV NEPA administered with DEX over initial and repeated cycles of HEC. ${ }^{7}$ This study led to the approval of IV NEPA (AKYNZEO $®$ IV) for prevention of acute and delayed nausea and vomiting associated with initial and repeat courses of HEC by the Food \& Drug Administration in April $2018 .{ }^{8}$

- This subsequent ongoing study was similarly designed to assess the safety of IV NEPA in patients receiving AC chemotherapy.

\section{OBJECTIVES}

\section{Primary}

- The primary objective of this Phase 3b study is to assess the safety and tolerability of a single dose of IV NEPA administered with DEX over initial and multiple cycles of $A C$ chemotherapy.

Oral NEPA is included as a control group to help interpret any unexpected safety finding in the IV NEPA group.
Secondary

- To describe the efficacy of IV NEPA in preventing CINV during the acute (0-24 h), delayed (25-120 h) and overall (0-120 h) phases after $\mathrm{AC}$ chemotherapy during initial and repeated cycles

\section{Exploratory}

- To evaluate the impact on economics and resource utilization through collection of Health Economics Outcomes Research (HEOR) parameters in initial and repeated cycles of $A C$ chemotherapy

\section{METHODS}

\section{Study Design}

- Phase 3b, multinational, randomized, double-blind, doubledummy, parallel-group safety study in chemotherapy-naïve women with breast cancer undergoing AC treatment

Patients are randomized to receive either IV NEPA or ora NEPA, both with DEX, prior to chemotherapy on Day 1.

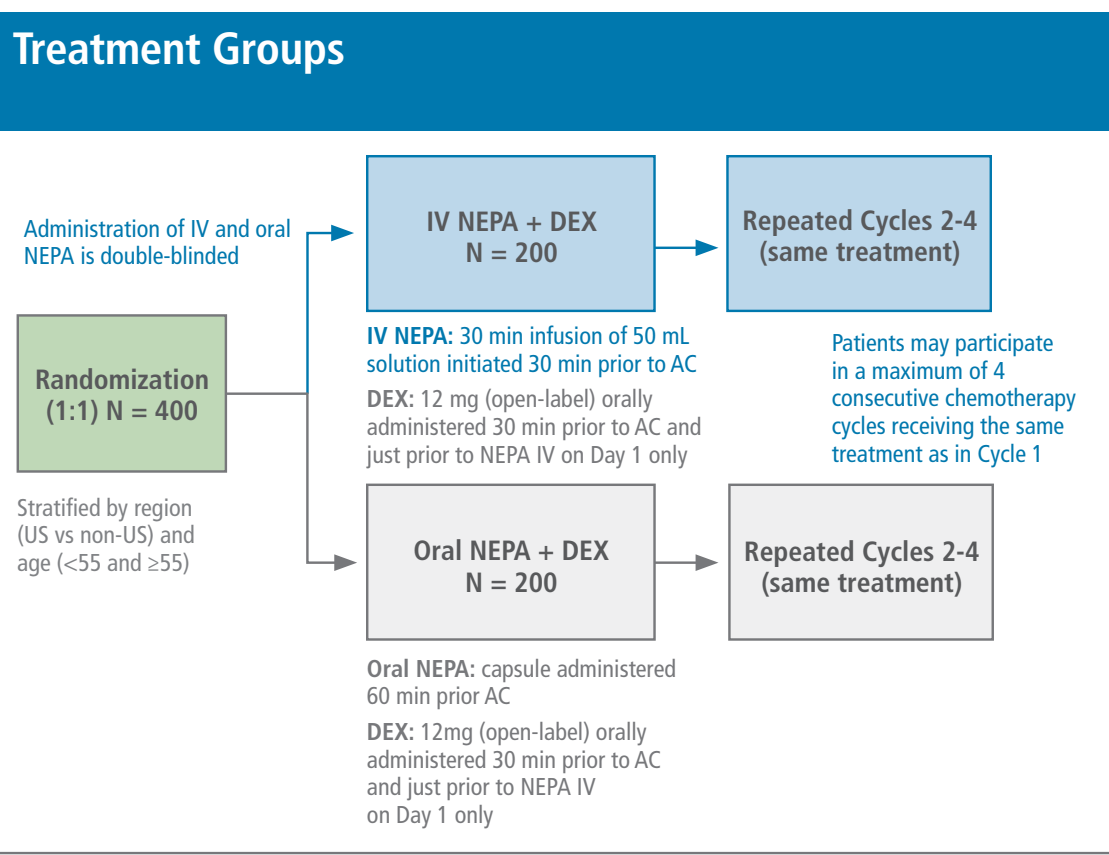

- A pharmacokinetic study confirmed that administration of fosnetupitant resulted in a similar increase in DEX exposure as that seen with netupitant: therefore, the DEX doses were adjusted the same for both treatment groups and in line with that recommended in the NEPA package insert.

Key Inclusion \& Exclusion Criteria

\section{Key Inclusion and Exclusion Criteria Prior to Cycle 1}

\begin{tabular}{|l|l|}
\hline Inclusion Criteria & Exclusion Criteria \\
\hline $\begin{array}{l}\text { Females } \geq 18 \text { years with breast } \\
\text { cancer }\end{array}$ & $\begin{array}{l}\text { Scheduled to receive: (i) moderately } \\
\text { emetogenic chemotherapy (MEC) or } \\
\text { HEC in addition to AC from 6h after } \\
\text { start of AC through start aof AC in next } \\
\text { cycle, (ii) radiotherapy to abdomen or } \\
\text { pelvis within 1 week prior to day 1 or } \\
\text { between days 1 and 5, inclusive, or (iii) } \\
\text { a bone marrow or stem-cell transplant } \\
\text { during the study }\end{array}$ \\
\hline $\begin{array}{l}\text { Histologically or cytologically } \\
\text { confirmed breast cancer, including } \\
\text { recurrent or metastatic. }\end{array}$ & $\begin{array}{l}\text { Receipt of any drug with potential } \\
\text { antiemetic efficacy within 24h before } \\
\text { day 1 or any systemic corticosteroids } \\
\text { within 72 hours prior to AC on day 1 }\end{array}$ \\
\hline $\begin{array}{l}\text { Naiive to moderately or highly } \\
\text { emetogenic antineoplastic agents }\end{array}$ & $\begin{array}{l}\text { Experienced any vomiting, retching or } \\
\text { nausea within 24h before day 1 }\end{array}$ \\
\hline $\begin{array}{l}\text { Scheduled to receive at least } \\
4 \text { consecutive cycles of an AC } \\
\text { combination regimen }\end{array}$ & $\begin{array}{l}\text { History or predisposition to cardiac } \\
\text { conduction abnormalities, except for } \\
\text { incomplete right bundle branch block }\end{array}$ \\
\hline ECOG Performance Status of 0 or 1. & $\begin{array}{l}\text { Severe or uncontrolled cardiovascular } \\
\text { diseases within 3 months prior to Day } \\
1, \text { including myocardial infarction, } \\
\text { unstable angina pectoris, significant } \\
\text { valvular or pericardial disease, history } \\
\text { of ventricular tachycardia, symptomati } \\
\text { congestive heart failure New York } \\
\text { Heart Association class III-IV, or severe } \\
\text { uncontrolled arterial hypertension }\end{array}$ \\
\hline $\begin{array}{l}\text { Patient shall be: a) of non- } \\
\text { childbearing potential or b) of } \\
\text { childbearing potential using reliable } \\
\text { contraceptive measures and having } \\
\text { a negative urine pregnancy test } \\
\text { within 24 hours prior to dose of } \\
\text { investigational product }\end{array}$ & $\begin{array}{l}\text { Known hypersensitivity or } \\
\text { contraindication to 5-HT, RAs (e.g., } \\
\text { palonosetron, ondansetron, } \\
\text { granisetron, dolasetron, tropisetron, } \\
\text { ramosetron), to DEX, or to NK, RAs } \\
\text { (e.g., aprepitant, rolapitant). }\end{array}$ \\
\hline
\end{tabular}

Assessments

- Safety

Treatment-emergent adverse events (TEAEs), physical examination, vital signs, and laboratory tests

- Efficacy

Efficacy parameters are evaluated at each cycle during the acute (0-24h), delayed (25-120h) and overall (0-120h) phases after the start of the AC chemotherapy

Endpoints include proportions of patients with

- Complete response (CR: no emetic episodes and no rescue medication)

- No emetic episodes

- No rescue medication

- No significant nausea (defined as maximum nausea intensity on a $100 \mathrm{~mm}$ VAS $<25 \mathrm{~mm}$ )

- No impact on daily life (NIDL) activities in the overall phase of Cycle 1 and 2 only as assessed by the Functional Living Index-Emesis (FLIE) questionnaire.

- HEOR

The following exploratory HEOR assessments will be obtained:

- Emergency Department (ED), Inpatient Admissions (IP) and length of stay (LOS)

- Lost work time and productivity assessed by the Work Productivity and Activity Impairment (WPAI) Questionnaire (Cycles 1 and 2 only)

- Disruptions in initiating or dose modification of intended next cycle of chemotherapy

\section{Statistical Analyses}

- No formal comparisons between treatment groups are planned for assessments of safety and efficacy. The presence of the oral NEPA control group is intended to help interpret any unexpected safety finding in the IV NEPA group.

- Adverse events will be listed, described and summarized by frequency tables.

- At each cycle, for each phase (acute, delayed, and overall), numbers and proportions (including $95 \% \mathrm{Cl}$ using Wilson score method) of patients with $\mathrm{CR}$, with no emetic episodes, with no rescue medication, and with no significant nausea will be descriptively summarized.

\section{ENROLLMENT \& REGISTRATION}

\section{- Enrollment of this international study began in March 201} with approximately 50 sites planned in the United States, and approximately 30 sites distributed in Russia, Ukraine, and Georgia.

- The study is registered at ClinicalTrials.gov (NCT03403712).

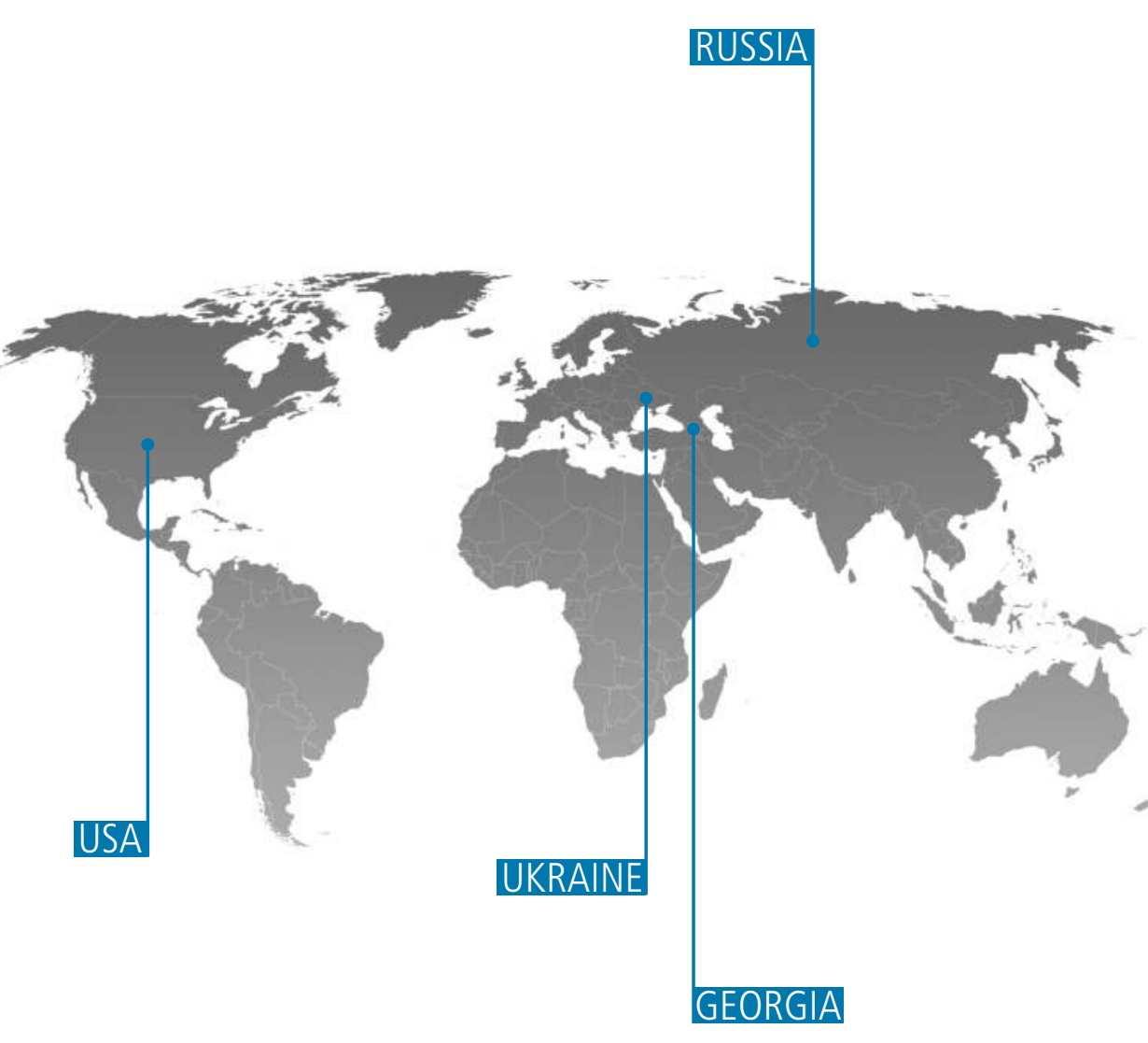

